\title{
Duloxetine Hydrochloride-Induced Oral Lichenoid Reaction: A Case Report
}

\author{
Nilima S. Kadam a Rahul A. Patil ${ }^{a}$ Abhijit N. Gurav ${ }^{a}$ Abhijeet Shete ${ }^{a}$ \\ Prashant D. Jadhav ${ }^{b}$ Ritam Naik Tari ${ }^{a}$ Suryakant Metkari ${ }^{\mathrm{c}}$ \\ Dhanashree Agarwal ${ }^{a}$
}

Departments of ${ }^{\text {a Periodontology, }}{ }^{\mathrm{b}}$ Prosthodontics and ${ }^{\mathrm{C} O r a l}$ Pathology, Tatyasaheb Kore Dental College and

Research Centre, Kolhapur, India

\section{Key Words}

Duloxetine hydrochloride · Drug-induced oral lichenoid reaction - Oral lichen planus

\begin{abstract}
Objective: To report the first case of duloxetine hydrochloride (DH)-induced oral lichenoid drug reaction (OLDR). Clinical Presentation and Intervention: A 57-year-old male patient presented with painful ulcerative lesions on the bilateral buccal mucosa of 2-year duration. The patient was on multiple drug therapy for his systemic ailments. After thorough evaluation for possible medical ailments and with the physician's consent, withdrawal of DH was done. The oral lesions were resolved after 2 weeks. Conclusion: In this case, DH induced OLDR.

(c) 2015 S. Karger AG, Basel
\end{abstract}

\section{Introduction}

Oral lichenoid drug reaction (OLDR) shares indistinguishable clinical and histopathological features with oral lichen planus (OLP); hence, it is often misdiagnosed as OLP [1]. A variety of cases have been reported in the literature of OLDR associated with the use of different sys- temic medications $[1,2]$. A newer antidepressant drug, duloxetine hydrochloride (DH), is a mixed serotonin and norepinephrine reuptake inhibitor. There has been a report of a cutaneous adverse reaction on the intake of $\mathrm{DH}$ (60 mg/day) [3]. However, there is no report of OLDR due to $\mathrm{DH}$. The present case reports OLDR due to DH. Written informed consent was obtained from the patient for the publication of this case report.

\section{Case Report}

A 57-year-old male patient presented to the Postgraduate Clinic of Periodontics with the main complaint of a burning sensation in the bilateral cheek mucosa for the previous 2 years. The patient had painful symptoms when consuming hot and spicy foods, but the pain was relieved on the intake of cold foodstuffs. Clinical history revealed oral lesions that were preceded by asymptomatic cutaneous lesions. The patient revealed a positive medical history for hypertension (Atenolol tablets, $25 \mathrm{mg} /$ day, since 15 years) and type 2 diabetes mellitus treated with metformin hydrochloride (500 mg, b.i.d.), since 2 months. Upon anamnesis, the patient reported the intake of $\mathrm{DH}$ for depression $(60 \mathrm{mg} /$ day) for more than 2 years. The initial dose of DH was $60 \mathrm{mg} / \mathrm{day}$, which was increased to $120 \mathrm{mg}$ (60 mg, b.i.d) by his physician 6 months after the administration of the initial dose. The dose was increased due to the underlying chronic depression. The patient noticed the presence of oral lesions a few weeks after the consumption of DH $(120 \mathrm{mg})$. A few months later the patient observed peeling of the buccal epithelium with areas of red

\begin{tabular}{ll}
\hline KARGER 125/s & $\begin{array}{l}\text { (c) 2015 S. Karger AG, Basel } \\
1011-7571 / 15 / 0244-0394 \$ 39.50 / 0\end{array}$ \\
$\begin{array}{l}\text { E-Mail karger@karger.com } \\
\text { www.karger.com/mpp }\end{array}$ & $\begin{array}{l}\text { This is an Open Access article licensed under the terms of the } \\
\text { Creative Commons Attribution-NonCommercial 3.0 Un- } \\
\text { ported license (CC BY-NC) (www.karger.com/OA-license), } \\
\text { applicable to the online version of the article only. Distribu- } \\
\text { tion permitted for non-commercial purposes only. }\end{array}$
\end{tabular}

Dr. Nilima S. Kadam

Department of Periodontology

Tatyasaheb Kore Dental College and Research Centre

New Pargaon, Kolhapur, Maharashtra 416137 (India)

E-Mail dr.nilima15@gmail.com 
Fig. 1. OLDR lesions of the right (a) and left (b) buccal mucosa at the initial visit.
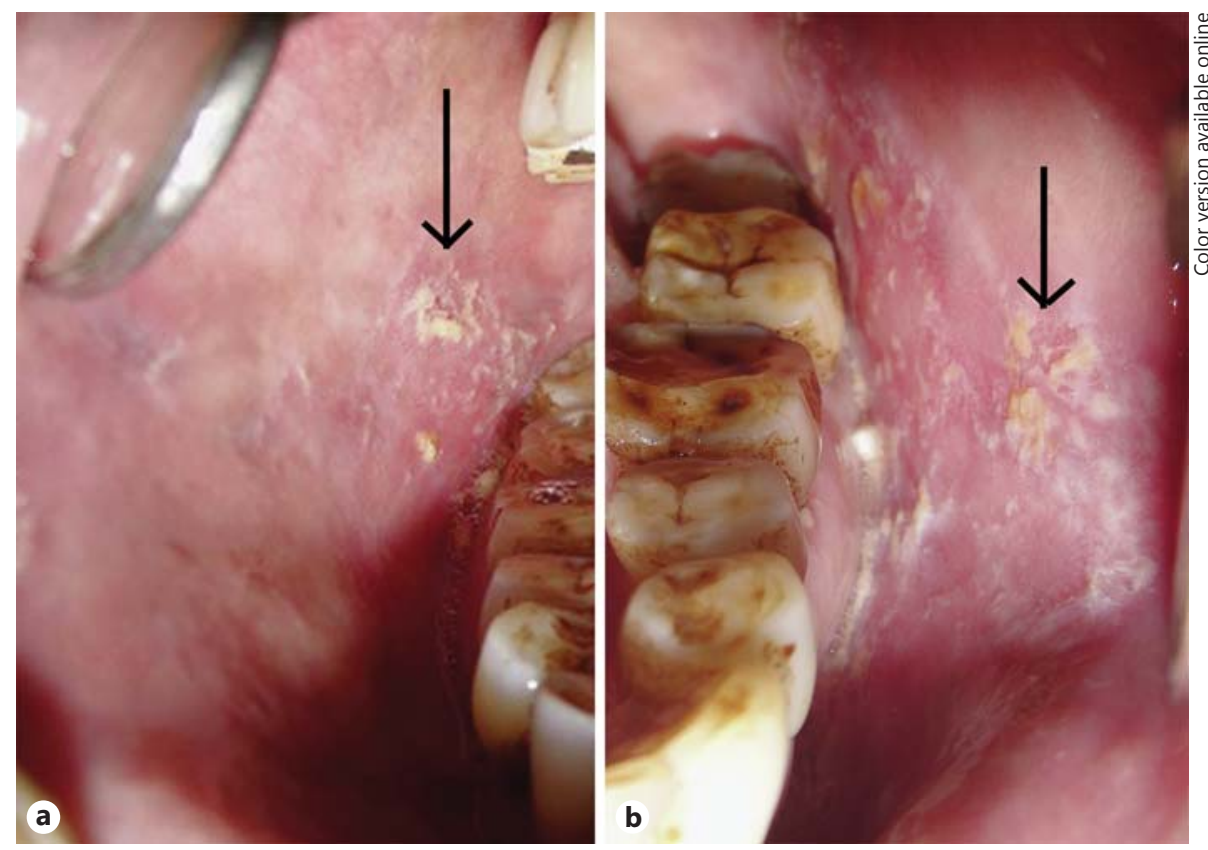

erosion. The patient sought medical help for the painful nature of ulcerative lesions. He was prescribed with various topical applications and multivitamin capsules, without positive outcome. Nonresponse to the medications caused anxiety to the patient. The cutaneous lesions were purplish polygonal papules with symmetrical distribution over the skin of the forearm. On intraoral examination, it was observed that the buccal epithelium was peeled, leaving behind multiple red erosive lesions (fig. 1). A polygonal-shaped ulcer was seen in the center of the lesions surrounded by an erythematous halo on the subsequent day visit. The healing period of the lesions was approximately 5-7 days followed by melanin pigmentation. Newer lesions occurred 10-12 days later, after healing of the initial lesions. The patient had observed a characteristic pattern of these lesions periodically. An incisional biopsy was taken from the left buccal mucosa. Microscopically, the section showed atrophic parakeratinized stratified squamous epithelium. The connective tissue showed a dense band of lymphocyte infiltration (fig. 2).

Pharmacological management of the oral lesions was unproductive, and medical history revealed the onset of the lesions within a few weeks after the commencement of $\mathrm{DH}$. Patch and provocation tests are the definitive tests for the diagnosis of lichenoid reactions (LRs), but the patient refused to undergo the above-mentioned tests. After thorough evaluation of all medications, the patient was asked to withdraw $\mathrm{DH}$ first. The lesions subsided within 2 weeks of withdrawal of $\mathrm{DH}$; hence the causative effect of other drugs was ruled out indirectly. The patient underwent psychological counselling and was reassured about the nature of the lesions. Presently, the patient is not under any medication for his chronic depression. He was advised to maintain meticulous oral hygiene. After the withdrawal of $\mathrm{DH}$, the patient was kept under periodic observation. After 15 months of reevaluation complete healing of the erosive lesions was noted (fig 3). A final diagnosis of OLDR of buccal mucosa with cutaneous involvement was made on the basis of clinicopathological correlations.

Drug-Induced Oral Lichenoid Reaction

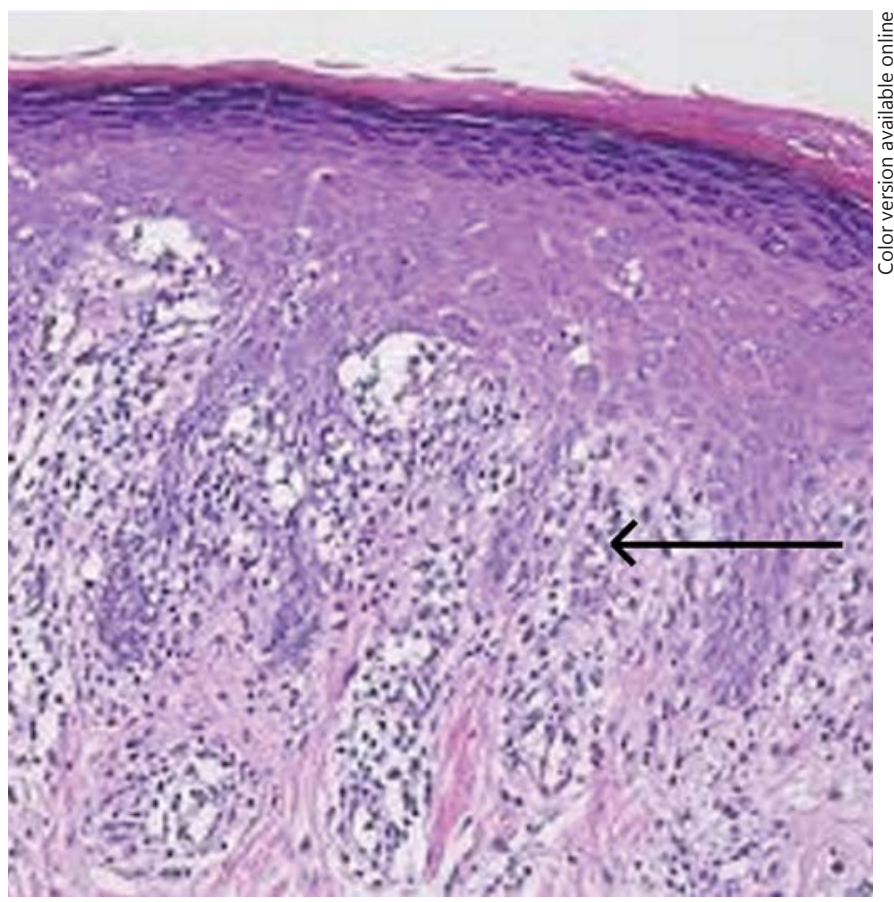

Fig. 2. Histological picture of the lesions.

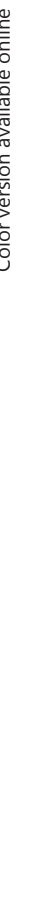


Fig. 3. Complete healing of the erosive lesions of the right (a) and left (b) buccal mucosa.
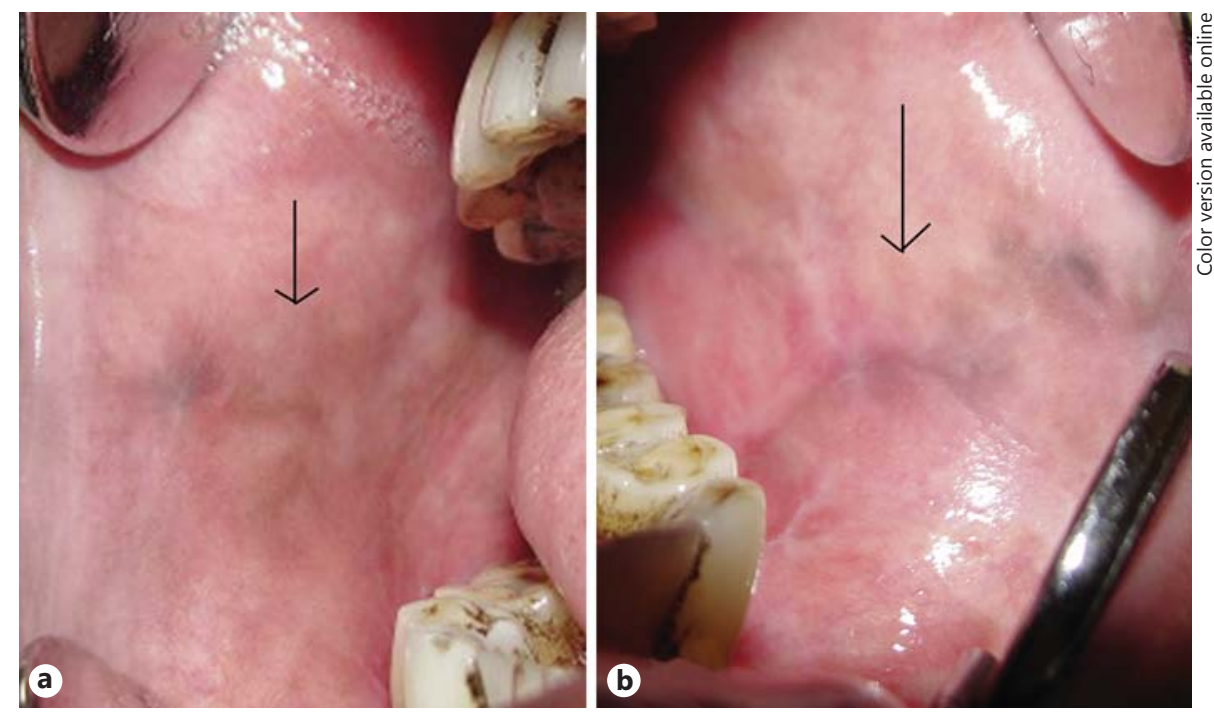

\section{Discussion}

The oral lesions were erosive, painful and persistent, involving the bilateral buccal mucosa. Complete resolution of the lesions occurred only after the withdrawal of $\mathrm{DH}$, which led to the diagnosis of OLDR. The OLDR induced by $\mathrm{DH}$ was possibly caused by the intraepidermal CD8+ T cells. These cells primed from previous antigens became ensnared and persisted at the mucosal site and later induced mucosal damage after cross-reacting with the drug [4]. LRs exhibit similar clinical and microscopic alterations to those of OLP, which resemble a delayed hypersensitivity reaction. The LRs are triggered by specific etiological agents, thus revealing a cause-effect relationship [1,2].

For the diagnosis of OLDR, recent or chronic exposure to a drug is essential. The latent period for the onset of lesions varies from weeks or months to years from the commencement of medication. OLDR lesions resolve after drug cessation [1]. Although OLDR shares similar clinicopathological features with OLP, its etiology, diagnosis and prognosis varies from those of OLP. This necessitates its appropriate diagnosis and further pertinent treatment. It is important for the clinician to keep OLDR patients under periodic observation, since malignant transformation is higher in OLDR $(0.4-6.5 \%)$ compared to OLP (05.3\%) [5].

The $\mathrm{DH}$ is a mixed serotonin and norepinephrine reuptake inhibitor approved by the United States Food and Drug Administration (FDA) for the treatment of depressive disorder. However, its clinical efficacy is subop- timal [6]. The most commonly observed significant adverse effects associated with $\mathrm{DH}$ are nausea, dry mouth, dizziness, constipation, fatigue, and decreased appetite [3]. Spielmans [7], in his meta-analysis, mentioned that $\mathrm{DH}$ as an antidepressant with analgesic properties for people with depression is not adequately supported, and further research is required to prove its efficacy.

There have been reports on OLDR caused by antihypertensive and hypoglycemic drugs $[1,2]$. In the present case, the patient reported lesions after the consumption of medication for his psychological illness. Hence, it is uncertain whether these psychological factors led to pathogenesis or were a consequence of the lesions. Considering all these factors, it was a diagnostic challenge to determine absolute certainty about a causative agent for OLDR among these medications or the psychiatric condition itself. The patient was highly anxious and depressed due to lack of resolution of the lesions in spite of previous treatment.

In the case of multiple suspected medications taken by a patient with LRs, the most recent medication should be targeted for initial investigation [1]. Hence, the offending medication for OLDR in the present case was $\mathrm{DH}$, as the instigation and diminution of the lesions transpired from the start and withdrawal of $\mathrm{DH}$. The erosive lesions were cleared and healed, with hyperpigmentation. Evaluation of the lesions after 15 months of follow-up revealed a similar picture, which suggests the lesions do not heal completely. This finding is consistent with other OLDR cases in the literature $[1,2]$. A final diagnosis of OLDR was made based on clinicopathological correlation de- 
rived from the criteria of Van der Meij et al. [8], as the lesion was clinically similar and histologically 'compatible with' OLP, with distinct etiology. In the present case the withdrawal of the offending drugs was essential. This was done with consideration of the risk-benefit potential of the disease and with the physician's consent. The patient underwent psychological counselling for his depressive disorder and was educated to assuage fears of potential malignancy and the contagious nature of the disease.

\section{Conclusion}

Based on this case, DH was the causative agent for OLDR. However, further evidence is needed to prove same.

\section{Disclosure Statement}

The authors have no conflicts of interest to declare.

\section{References}

1 Schlosser BJ: Lichen planus and lichenoid reactions of the oral mucosa. Dermatol Ther 2010;23:251-267.

-2 Serrano-Sánchez P, Bagán JV, Jiménez-Soriano, et al: Drug-induced oral lichenoid reactions. A literature review. J Clin Exp Dent 2010;2:e71-e75.

3 Oulis P, Masdrakis VG, Karakatsanis NA, et al: Duloxetine-induced cutaneous adverse reaction. J Clin Psychopharmacol 2008;28:104105.
Shiohara T, Mizukawa Y: The immunological basis of lichenoid tissue reaction. Autoimmun Rev 2005;4:236-241.

5 Fitzpatrick SG, Hirsch SA, Gordon SC: The malignant transformation of oral lichen planus and oral lichenoid lesions: a systematic review. J Am Dent Assoc 2014;145:45-56.

6 Lacasse JR, Leo J: Serotonin and depression: a disconnect between the advertisements and the scientific literature. PLoS Med 2005;2: e392.
Spielmans GI: Duloxetine does not relieve painful physical symptoms in depression: a meta-analysis. Psychother Psychosom 2008; 77:12-16.

8 Van der Meij EH, Mast H, van der Waal I: The possible premalignant character of oral lichen planus and oral lichenoid lesions: a prospective five-year follow-up study of 192 patients. Oral Oncol 2007;43:742-748. 